\section{Free Barium in and Evaporated from Oxide Cathodes}

DURING 1945, in connexion with experiments on thermionic emission from electrodes other than the cathode in small radio valves, we had occasion to make measurements on the quantity of free barium evaporated from the cathode, and also the amount actually adsorbed on or distributed in the bariumstrontium oxide coating. In view of the theoretical importance of the latter in connexion with the electrical conductivity of the coating treated as a semi-conductor (investigated by D. A. Wright, whose results are at present in the course of publication), we feel that our results have become of more general interest. Previous measurements by Berdennikowa $^{1}$ and Clausing ${ }^{2}$ did not distinguish between the barium in the cathode coating and that evaporated, while Prescott and Morrison ${ }^{3}$, who made the distinction, used cathodes with free nickel distributed through the coating and activated them in an unusual manner by heating in methane. This may have produced excess barium, which could alloy with the nickel in the coating.

The method of estimation used by us was that of Berdennikowa, to treat the cathode in water vapour and measure the amount of hydrogen produced. The difference between our method and his was that provision was made for dropping the electrode surround. ing the cathode, or the cathode, into a side tube attached to the pumping system and sealing the actual valve off, so that only the barium on the appropriate electrode was estimated.

The results given are the mean of six determinations, the probable error being estimated in the usual manner. The barium evaporated from $0.8 \mathrm{sq}$. $\mathrm{cm}$. of barium-strontium oxide, with an activation of 1 hour at $950^{\circ} \mathrm{C}$. approximately and emission current of 50 milli-amp., from cathodes made of different core metals was as follows :

\begin{tabular}{|c|c|c|c|c|}
\hline & $\begin{array}{l}\text { Commercial ' } O \text { ' } \\
\text { nickel. (Nickel }+ \\
0 \cdot 12 \text { per cent mag- } \\
\text { nesium and traces } \\
\text { of other impurities) }\end{array}$ & Platinum & $\begin{array}{l}\text { Nickel } \\
+0 \cdot 2 \\
\text { per cent } \\
\text { silicon }\end{array}$ & $\begin{array}{c}\text { Pure } \\
\text { nickel }\end{array}$ \\
\hline$\mu$ gram (mean) & $3 \cdot 4$ & 0.62 & $1 \cdot 6$ & $1 \cdot 03$ \\
\hline Probable error & $0 \cdot 3$ & 0.09 & $0 \cdot 23$ & $0 \cdot 15$ \\
\hline
\end{tabular}

The effect of the magnesium and silicon in producing free barium is very apparent from these figures.

The barium content of the coating was measured on cathodes with $0.6 \mathrm{~cm} .^{2}$ of coated area and given a similar activation, the core in this case being the ' $\mathrm{O}$ ' nickel. Total quantity of barium in the coating was $0.4 \mu \mathrm{gm}$., with a probable error of $0.07 \mu \mathrm{gm}$., which corresponds to $3 \times 10^{15}$ atoms per $\mathrm{cm}^{2}$, $3 \times 10^{17}$ atoms per $\mathrm{cm} .^{3}$ or 0.01 per cent by weight of the coating.

This work will be published in more detail else. where in due course.

R. O. JENKINS

R. H. C. NEWTON

Research Laboratories,

General Electric Company, Ltd.,

Wembley.

Oct. 14

${ }^{1}$ Berdennikowa, Phys. Z. Sovjetunion, 2, 77 (1932). "Clausing, "Electron Emission and Adsorption Phenomena", 348
(J. H. De Boer).

${ }^{3}$ Prescott and Morrison, J. Amsr. Chem. Soc., 60, 3047 (1938).

\section{A Simple Method of Producing Wide-Band Frequency Modulation}

THE resistance-capacity tuned oscillator is well known as a very good generator of audio-frequency oscillations. In a recent communication by Rakshit and Bhattacharyya ${ }^{1}$ it was pointed out that the con. ventional circuit of a three-phase system, with components selected for producing audio-frequency oscillations, invariably generates radio-frequencies by virtue of the unavoidable stray and inter-electrode capacities. In fact, with the simple three-phase oscillator it is impossible to generate audio-frequencies unless certain modifications are introduced in the circuit. It was further pointed out that the threephase radio-frequency oscillator can easily be made to generate frequency-modulated oscillations by varying the tuning resistance of one of the oscillator stages by the modulating voltage.

When the three stages of the oscillator are identical, the anode load of each valve being composed of resistance $r_{1}$ shunted by capacity $c_{1}\left(c_{1}\right.$ includes the stray and inter-electrode capacities involved in the system), it was shown that the oscillations produced are of radio-frequency given by

$$
f=\frac{\sqrt{ } 3}{2 \pi c_{1} r_{1}}
$$

If the anode load resistance of any one stage be changed from $r_{1}$ to $r$, without altering any other part of the circuit, the frequency can be shown to change to

$$
f=\frac{1}{2 \pi c_{1} r_{1}} \sqrt{1+\frac{2 r_{1}}{r}} .
$$

It was therefore suggested in the previous com. munication that a very simple method of producing frequency modulation would be to shunt any of the three oscillator valves by a triode and apply the modulating audio voltage on the grid of this triode modulator. Faithful modulation would, however, require linearity between change in oscillator fre. quency and amplitude of modulating voltage. Further, there should not be appreciable amplitude modulation introduced in the process. These conditions have been found to be very closely satisfied

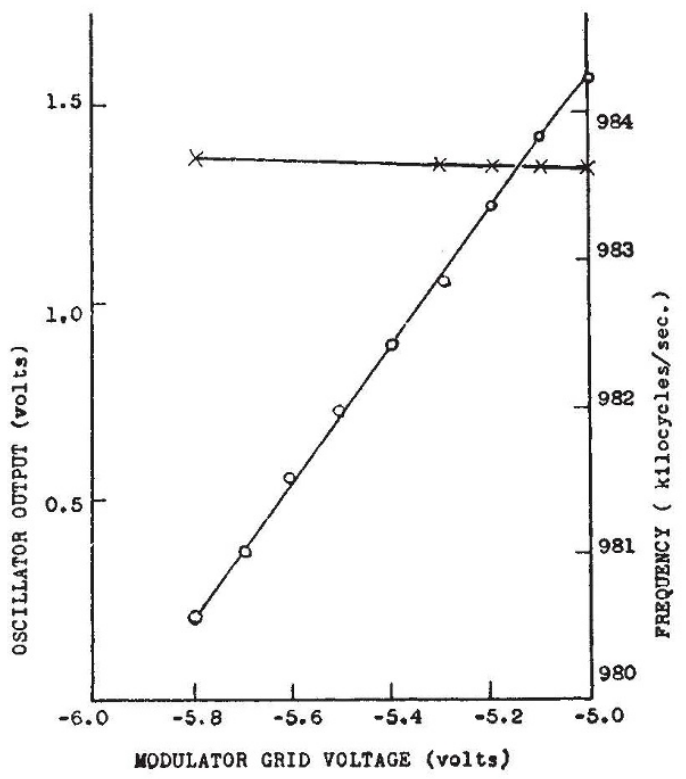

